pain in the hip, flattening of the trochanter, effusion in the surrounding tissues in front and rear of trochanter, crepitus on extension in the comparatively young, much contusion of soft parts, from a major form of cause as a violent fall, blow or pressure directly on the trochanter denote extracapsular fracture with tendency to union of ligament.

Then again a slight shortening of the limb and eversion of foot, with much pain on attempted motion, absence of crepitus, slight ability to raise the limb or stand upon the foot, great effusion in front and rear of trochanter, from a violent direct injury to the trochanter with contusion of soft parts, indicates impacted fracture.

Diagnosis of Impacted Fracture of the Cervix Femori. - The two cases of impacted fracture of the neck of the femur which came under my observation both resulted from indirect and violent causes. In one the patient was 70 years old, and had a violent fall directly on the trochanter of that side. The trochanter was found on comparison with the opposite side to be flattened and depressed, and very tender on pressure. There was considerable swelling back of the trochanters, and in front below Poupart's ligament there was great swelling and much pain and tenderness. There was entire loss of power over the limb and inability to stand on it.

Shortening of the limb was imperceptible and eversion was entirely absent. The injury occurred more than six years since, and the patient has never recovered the use of the limb and is still comparatively bed-ridden.

The second case occurred in a comparatively young person with identical symptoms as the former, and has never recovered a fair degree of locomotion in the limb since the injury.

Complications.-One of the most serious complications observed in my experience has been symptomatic fever following the injury. It is more apt to occur in the extra than the intracapsular variety, becauses the causes are of a more violent character, and the anatomic structures of the part are more extensively lacerated.

I never saw but one case of protracted fever following intracapsular fracture in an aged person recover, and that was in the case of a woman aged 85 years. She recovered and lived in comparative health and comfort to reach 90 years, and then died from hemiplegia.

A temperature ranging from 101 to 103 degrees, a quick pulse, pain and restlessness denote serious organic changes going on in the injured structures, that if permitted to progress will continue until extensive inflammation, effusion of exudates and suppuration intervene.

Treatment of Fractures of the Neck of the Femur.There is no class of fractures that require the exercise of more judgment in their treatment or more accuracy in diagnosis than fractures of this kind.

In one variety of fracture, the extracapsular, in those below middle life we can adopt means with safety to bring about union. To adopt the same means in intracapsular fracture in the aged would insure certain death. Hence the importance of an accurate differential diagnosis.

Treatment of Intracapsular Fractures.-In my own experience a good rule to work by in treating intracapsular fractures of the cervix femoris in the aged, is to so manage the case from the beginning as not to expect union of the fractured bones, but on the contrary to so conduct the management of the case as will, if possible, insure a good, strong, false joint, by which after a time the patient can regain a fair degree of locomotion for the balance of life. To bring about this desirable object, the pelvis from the anterior superior spinous process is enveloped with a broad flannel roller four inches wide and fifteen feet long, applied down below the trochanters. This flannel bandage gives comfort by the support that it affords the fractured bones, and the prevention of too much motion, and gives opportunity to the soft parts involved to throw out adhesive exudations. This is the full extent of the apparatus to be applied. As for the balance of treatment, pillows long and short, small and large, are to be relied on for splints and supports. Comfort of position is to be the guiding rule in the management of this class of cases. The ingenuity of surgeon and nurse will be taxed to so arrange the pillow splints as to insure comfort, relieve pain and secure sleep. When these objects are accomplished all has been accomplished that judgment and experience can do until inflammatory action subsides, and the process of fibrinous exudation is completed, and then the false joint is ready for use. To attempt, on the contrary, to confine this class of patients in a stiff apparatus with the view of accomplishing that which no power can ever effect, a union of bone or ligament, is to condemn our patient not only to unnecessary suffering but to certain death.

In the treatment of extracapsular fracture from violent and direct causes in the comparatively young, we may calculate with a degree of certainty on ligamentous union, provided the method adopted will maintain perfect adaptation of the fragments and we can adopt such methods and apparatus as will insure this end, without fear of detriment to the patient as in the former case. After the pelvis has been firmly enveloped in the broad flannel roller, as in the former case, then Buck's extension apparatus is applied and the extension maintained until union takes place, which is usually about six weeks.

In impacted fracture my method of treatment has been to envelop and support the pelvis and fractured hip bones by means of the flannel bandage, which I consider better and more comfortable than a simple band, and for the purpose of supporting the limb and the prevention of motion, which might cause dislocation of the fractured bones, Two sand bags, the longer, external, reaching from above the pelvis below the foot; the other, shorter, reaching from a little below the external genitals on the inside of the limb below the foot. These arrangements appear to meet the desired ends better in my own experience than any other.

\section{THE TREATMENT OF FRACTURES OF THE SHAFT OF THE FEMUR.}

Read in the Section on Surgery and Anatomy at the Forty-fifth Anuual Meeting of the American Medical Association, held at San F'rancisco, Jane 5-8, 1894.

BY LEWELI,YN ELIOT, A.M., M.D.

SURGEON TO EASTERN DISPENSARY; CONSULTANT TO ST. ANNE'S INFANT ASYLUM, ETC., WASHINGTON, D. C.

Our chairman having paid the high compliment of assigning the subject of the "Treatment of Fractures of the Shaft of the Femur" to me, I shall, within the time allotted, place my views before the Section in the briefest possible manner. 
The causes, the symptoms and the diagnoses of fracture of the femur being entirely foreign to my subject, no mention will be made of them. We shall likewise exclude from consideration all fractures of the femur not located between the lesser trochanter and the condyles. Although every variety of fracture is found in this bone, the transverse and the oblique are the most frequent; these fractures may be either simple, comminuted or compound.

Having made our diagnosis, we must have the patient's bed arranged so as to allow permanent and continuous traction to be employed. This traction, in the case of adults, may be effected, after the proper adjustment of the fractured ends of the bone, through the employment of the apparatus of either Liston, Desault, MacIntyre, Thomas, the Smith anterior, the Hodgen suspension, Buck, Boyer, Neill or the double inclined plane of Esmarch, Gross, or others, the foot of the bed being raised so as to insure counter extension. In infants, either Hamilton's apparatus or vertical extension will give satisfactory results. To enter into a description of the various devices employed in the treatment of fractures of the femur would be of no interest to you, since all are familiar with them. The employment of permanent dressings, plaster-of-paris, silicate of soda or others of a like nature, I do not think justifiable before the third week, when union is sufficiently strong to warrant their application, although many surgeons employ them from the start, and I would hesitate quite a while before I would use any of them previous to the establishment of union of the fragments. Objections will readily present themselves. Should a compound fracture present itself, I should be still slower in applying a permanent dressing.

The question of suturing or pegging fragments in cases of compound fracture, and of amputation, may be settled in a few words. Where the fragments can be properly and accurately adjusted and the blood supply to the limb remains good, the fragments should be sutured or pegged and the wound treated by the open method; where, however, the soft parts are lacerated and the vessels supplying the $\operatorname{limb}$ are divided, amputation should be resorted to early, before the patient's strength is wasted through secondary hemorrhage, gangrene or other causes.

The treatment of fractures of the shaft of the femur resolves itself into the following: A suitable bed, accurate apposition of the fragments, the proper application of the splint and extension, good nutritious food, and unless the case is one requiring amputation, the results will generally be satisfactory, although shortening occurs in very many cases.

There is one question in relation to extension in fractures of the femur to which I would like to call attention. This is the matter of the priority of the application of adhesive plaster in extension. The generally accepted opinion is that Dr. J.K. Swift is entitled to the credit of first using it and Prof. S. D. Gross, in his "The Anatomy, Physiology and Diseases of the Bones and Joints," page 50, published in 1830, puts forth his claim as follows: "In complicated fractures of the leg, it not unfrequently happens that the soft parts about the ankle are so much contused or otherwise injured as to render it impossible to employ the usual extending bands. When this is found to be the case, the difficulty may usually be remedied by applying along each side of the leg, as high up as the seat of fracture will admit, a piece of strong muslin, about two feet and a half in length, two inches and a half in width, and spread at one of its ends with adhesive plaster. The part which is applied on the limb should be confined by three or four circular strips, so as to keep it firmly in its place, and equalize the extending power. The free extremities of the extending bands should then be tied under the sole of the foot and be secured to the block or bar which connects the lower ends of the splints. This mode of making extension, for which we are indebted to the ingenuity of my friend and preceptor, Dr. Swift, of Washington, will, I am fully persuaded, be found highly useful in practice and satisfactorily obviate the inconvenience to which I have just alluded."

Now, for more than twenty years, I have endeavored to adduce evidence so as to accord the credit to Dr. Alexander McWilliams, of Washington, and to that end have searched books and journals and papers. At the time when success seemed to crown this research I find published evidence which dissipates all contention.

The following appears in "Medical and Chirurgical Observations," as an appendix to a former publication, by Benjamin Gooch, Surgeon, London, published about 1771: "To answer the same purpose I have confined one end of a strong strip of sticking plaster of a suitable length and breadth under a circular piece of the same, about the middle of the side of the foot, carrying it over the heel, up the leg and confining the other end above the calf with another circular plaster. First gradually bring down the muscle gastrocnemius as far as they will readily yield, giving the limb at the same time the position described in my treatise on wounds. On the like occasion I have also fixed one strap by the circular piece about the foot and another by that above the calf of the leg, passing the one through a slit in the other, and using them as the uniting bandages; but then two more circulars are requisite to confine the other ends of the longitudinal strips securely."

That the studies and this publication of Gooch did not receive attention from surgeons and other writers is evident from the fact of so many others afterwards working in the same line of thought, each unconscious of the work of the other. Among those workers was Dr. Alexander McWilliams, who treated in 1827 , a case of fracture of the femur by this method of extension, at the Washington Almshouse. Failing to establish the claim of Dr. McWilliams to priority in the application of the idea of extension by means of strips of adhesive plaster, I will present such evidence as I possess, all derived from letters in my possession, to establish his claim to the credit of being the first surgeon in the United States to put into practice this idea. At that time (1827) according to the letter of Dr. Hall, the recognized surgeons of this country knew nothing of this method, and indeed as late as 1836 , M. Larray mentions the method only to condemn it, as will be seen in the extract taken from the Minutes of the Société Royale de Medicine of June 21, 1836.

In a letter under date of Jan. 9, 1875, Dr. Noble Young, of this city, writes: "In regard to the matter of the invention and application of adhesive strips for the purpose of extension in cases of fracture of the femur, by the late Dr. Alexander McWill. iams, I have to state it is within the recollection of 
his family that it occurred prior to 1829 ; they know this by circumstances impressing it indelibly upon the memory. He sent a model explaining the application to Paris by Dr. Hall, brother of the late David A. Hall, and received a letter from the French Academy of Medicine, congratulating him and thanking him for his valuable contribution. This letter has been mislaid only within the last few years. I may add that Dr. Jos. Barrows remembers its application at the almshouse in this city before 1828, when he was a student there."

Dr. James C. Hall, under date of Feb. 15, 1878, writes: "My evidence as to the application of adhesive strips as a means of extension in the treatment of fractures by Dr. McWilliams must be circumstantial. I came to Washington in October, 1828. After graduating (1827) I was for one year a resident physician and surgeon in the Philadelphia Almshouse, now Blockley Hospital. The visiting surgeons and clinical lecturers were Profs. Gibson, Horner, Rhea, Barton and Harlan. Very many and all kinds of fractures were treated in the House, and I am positive that I never heard McWilliams' mode either mentioned or practiced during my term of service. . . . My recollection is almost positive that my first knowledge of Dr. McWilliams' use of the strips as a means of extension was derived from an article which the Doctor published in a newspaper here, I thought it was the National Intelligencer, but Dr. Toner has searched for it and not found it there. This has not weakened my conviction that Dr. McWilliams published in some paper an account of his method of treating fractures of the femur.

Dr. Joseph Barrows, under date of June 6, 1878, writes: "Excuse my apparent neglect in not answering until now your letter in reference to the use of adhesive plaster in fractures of the lower extremities. In the year 1827 , I was one of the resident students in the Washington Asylum or Almshouse, of which Dr. Alexander McWilliams was the attending physician. Dr. McWilliams at that time exhibited and used adhesive plaster for the purpose above indicated."

In the Archives Généralés de Médicine, Book ii, p. 247, 1836, I find : Sociétié Royale de Médicine, Paris, séance du 21 Janv: "Rapport de M. Larray sur un appareil à extension continue pour les fractures des extrémités inférieures; par le Docteur Williams de Washington.-Cet appareil est une copie àpeuprès entierè de I' appareil de Boyer. La seule différence consiste dans une attelle interne qui se fixe à la traverse sur laquelle la vis s'appuie. M. Larray blâme la methode en général et tous les appareils qui s'y rattachent. Il n'adopte pas d'avantage le double plan incliné, et prefère toujours sou appareil inamovible."

Dr. B. Troutman, of Philadelphia, Pa., at my request called upon Prof. Gross, asking him for some definite data of Dr. Swift's application of this method of extension and he writes under date of $J$ une 27, 1879: "I called on Dr. Gross several times, but he always happened to be out of town, but last week I called again and saw him. He told me that Dr. Swift employed adhesive plaster in complicated fractures first in 1829."

The record of the Almshouse shows in the morning report of July 18, 1827 : "Admitted P. Boady, 40 years. Report of July 21, 1827: Fracture femur."
This is evidently one of the cases to which Dr. Joseph Barrows refers in his letter.

In nowork on surgery of this date-1827 to $1836-$ have I found any reference to this method of extension, so it is very evident that there had been no published development of the idea until Dr. McWilliams sent his model, a doll baby with the apparatus: applied, to Paris. Dr. J. F. May was present at the presentation and verbally testified to the favorable reception accorded it.

To my satisfaction, I have established the following facts: 1, Dr. Gooch was the first to employ adhesive plaster as a means of extension in fractures; 2 , the idea was allowed to pass into oblivion; $3, \mathrm{Dr}$. Alexander McWilliams, of Washington City, was. entirely ignorant of the work of Dr. Gooch; 4, Dr. McWilliams developed and put in practice the idea in $1827 ; 5$, the claim of Dr. Swift is too vague to carry weight with it; and 6 , the published report of the Société Royale de Medicine is the first published account of the method after its revival by Dr. McWilliams.

\section{TREATMENT OF OPEN OR COMPOUND FRACTURES.}

Read in the Section on Surgery and Anatomy, at the Forty-fifth Annual Neeting of the American Medical Association, held at San Francisco, June 5-8, 1894.

BY HENRY H. MUDD, M.D.

sT. LOUIS, Mo.

An open wound communicating with a fractured bone is a serious complication. Every effort is directed to its closure by sound healing. Its importance and the difficulty of its management is determined largely by the amount of injury inflicted upon the soft tissues about the fracture, and by the extent of the comminution of the bone. This open wound is usually determined by the violence which inflicts the fracture, but may result from ulceration. An oblique fracture where the skin has been torn by the sharp angling of the bone, with or without impact against an external object, offers a good opportunity to convert a compound into a simple fracture.

Fractures by direct violence which is not crushing, even if the bone is comminuted, present often good opportunity for the immediate closure of the wound. The soft parts are not necessarily much injured by such a fracture. This is especially true where the bone is supericial.

Extensive lacerations and contusions of the soft parts with a small or a large wound of the skin preclude an effort at immediate closure of the skin wound. They demand drainage. Even in such conditions a compound fracture may occasionally be promptly converted into a simple one by the agglutination of structures contiguous to the fracture, though the skin opening may remain free for drainage.

Absolute cleanliness is the first requisite in an attempt to convert a compound into a simple fracture. A razor, soap and water, are essentials, and must be well used in order to cleanse the skin. The purity of the water used in washing the wound is of first importance. The removal of extraneous matter from the wound may be accomplished by a wash of hot water, but where grease, cloth, and dirt of various kinds are adherent to the raw surfaces, the fingers, forceps, etherial soap, turpentine, and sublimated washes may fail to accomplish perfect cleanliness, 